\title{
Different technologies for the treatment of PAH contaminated sediments and consequences on human health individual risk
}

\author{
D. Cocarta ${ }^{1}$, I. A. Oprea ${ }^{1,2}$, M. Ragazzi ${ }^{2}$, G. Andreottola ${ }^{2}$, \\ G. Ziglio ${ }^{2}$, A. Badea $^{1} \&$ T. Apostol ${ }^{1}$ \\ ${ }^{1}$ University 'POLITEHNICA' of Bucharest, Romania \\ ${ }^{2}$ University of Trento, Italy
}

\begin{abstract}
Contaminated soils turn out to be a serious public health problem. For this reason, in the present work two aspects are illustrated. The first one regards different techniques for soil/sediment remediation. The sediments taken into account are contaminated by polycyclic aromatic hydrocarbons. The second aspect regards the influence of those on individual human health risk.

The technologies used in the experimental work are based on chemical and electrochemical oxidation. The considered exposure pathway for the assessment of the individual risk is soil ingestion. A few concentrations of total PAHs and $\mathrm{BaP}$ were considered in order to exemplify the influence of different technologies for soil remediation and effects on exposure through the soil ingestion pathway.

Assuming that the impacted area could be dedicated to a specific use, ingestion exposure pathway for organic pollutants as PAHs is one of the most significant. Moreover, the ingestion is an essential pathway of exposure considering that $\mathrm{B}(\mathrm{a}) \mathrm{P}$ carcinogenicity for the ingestion exposure pathway is one order of magnitude higher than the one for the inhalation.

Based on the results of this study, both chemical oxidation and electrochemical oxidation proved to be effective in the remediation of the sediments of concern. Additionally, the possibility of using the human health risk assessment as a tool in decisional criteria was underlined. The individual risk was assessed considering the $\mathrm{HRA}_{\mathrm{IRC}}$ software developed through an international $\mathrm{PhD}$ and some laboratory analyses performed at the Civil and Environmental Department of the University of Trento, Italy.
\end{abstract}

Keywords: contaminated soils remediation, risk assessment, BaP, sediments. 


\section{Generalities}

Polycyclic aromatic hydrocarbons (PAHs) are a group of organic molecules composed of fused benzene rings, classified among hydrophobic organic compounds (HOCs). PAHs can derive from many industrial activities, as combustion of waste and fossil fuels, production of coke, asphalt or coal tar, fuel processing, as well as oil spills. Once they are released in the environment, PAHs tend to persist and occur in natural media such as soil, sediments, water and air, resulting in a widespread distribution; in particular, due to their hydrophobic nature, low water solubility and high $\mathrm{K}_{\mathrm{ow}}$ they can become rapidly associated with sediments [4-6]. PAHs are regarded as persistent organic pollutants (POPs), and the environmental persistence increases with ring number; it is also reported that the greater the number of benzene rings in the PAH molecule, the greater the resistance to degradation $[2,6]$.

Land can become contaminated because of many human activities. In past times mining, quarrying, industrial activity and waste dumping were carried out with little regard to impact on the land. Agriculture and contaminants from the atmosphere can also impact on land and become a source of contamination. The disposal of industrial and domestic waste in landfill sites can result in the contamination of groundwater as pollutants can become concentrated into liquid that leaches from the site.

The aim of the experimental investigation presented in this paper was to assess the effectiveness and the feasibility of two different remediation techniques, chemical oxidation and electrochemical oxidation, for the remediation of fluvial sediments contaminated by polycyclic aromatic hydrocarbons (PAHs). Additionally, it was evidenced the importance of using risk assessment as a tool for decision-makers.

\section{Chemical oxidation}

Chemical oxidation is a remediation technique that uses chemicals (named oxidants) to mineralize organic pollutants by redox reactions. It is considered effective for the remediation of many types of hydrocarbons and organic pollutants, including halogenated compounds and recalcitrant contaminants, like PAHs. The oxidants that are most commonly used for environmental purposes are ozone, hydrogen peroxide, permanganate and activated persulfate [2].

In order to investigate the effectiveness of this technique, two sets of experiments were conducted during this experimental investigation: batch tests and column tests. The batch tests were conducted in conditions of soil slurry. Several laboratory tests were performed in order to estimate the removal efficiency under different conditions, with the following liquid reactants: a) hydrogen peroxide $\left(\mathrm{H}_{2} \mathrm{O}_{2}\right)$ (addressed as HP tests); b) modified Fenton's reagent (MF tests); c) potassium permanganate (PP tests) and d) activated sodium persulfate (AP tests). Also some combinations of these chemicals were tested as remediation agents, e.g. potassium permanganate and hydrogen peroxide (PPHP test), or activated sodium persulfate and modified Fenton's reagent (APHP). 
Each batch test was conducted on a $30 \mathrm{~g}$ sample of contaminated soil placed in a $100 \mathrm{~mL}$ reaction bottle. After adding chemical agents (oxidants and where necessary, the catalysts), the soil slurries were brought to a normalized volume of $100 \mathrm{~mL}$ by adding deionized water. During the tests, a complete mixing was ensured by the use of magnetic or orbital shakers to allow a perfect contact between oxidants and contaminants. The reactions were allowed to continue until the complete consumption of all chemicals. For each reactant the tested dosages ranged from 25 mmols to 200 mmols. For the tests with modified Fenton's reagent and activated persulfate, which required the use of a catalyst, a solution of chelated ferrous ions was added to the samples soon after the oxidant agent. Ferrous ions were obtained from ferrous chloride salts $\left(\mathrm{FeCl}_{2}\right)$, while catechol was used as chelating agent. Two molar ratios catalyst:oxidant were considered for modified Fenton's reagent, equal to 1:100 (MF100 tests) and to 1:50 (MF50 tests). For the activated sodium persulfate tests, a 1:25 catalyst:oxidant molar ratio was used.

Chemical oxidation column tests are very important since they allow evaluating the treatment effectiveness in conditions similar to in situ conditions, as for soil density, permeability and contact between pollutants and oxidants. Therefore, the removal efficiencies evaluated with these tests must be considered more representatives of real in situ remediation conditions. Nevertheless, since some preliminary tests showed that the sediment permeability was too low to allow a regular flux of liquid reactants across, only gaseous ozone was tested in the column tests. The column tests were conducted on $100 \mathrm{~g}$ sediment samples with a transparent PVC column (internal diameter $2.5 \mathrm{~cm}$, length $30 \mathrm{~cm}$ ), the ozone was produced by an ozonator from pure oxygen, provided by an oxygen cylinder. During tests the oxidant dose was regulated by changing the exposure time: two tests were performed with durations of 3 and 6 hours respectively, corresponding to a total ozone dose of 0.25 mols and 0.5 mols. The main results obtained across the presented remediation technique are presented in the next paragraphs.

\section{Electrochemical oxidation}

Direct Current Technologies (DCTs) are techniques for contaminated soil remediation, in which an electrical field is created in the polluted medium by applying a low-voltage direct current (DC) to electrodes placed in the ground $[7,13]$. The application of an electrical field to a soil has several complex physical and chemical effects, which include water electrolysis, electroosmosis, electromigration, electrophoresis, changes in soil $\mathrm{pH}$ and geochemical reactions. During the electrochemical treatment of a contaminated soil, the soil-pore water system can be considered as an electrochemical cell, in which oxidation and reduction reactions occur, water electrolysis providing the partners for the redox reactions. In an electrochemical cell, hydrogen peroxide can be produced as a result of redox reactions and in particular by the reduction of $\mathrm{O}_{2}$, according to the following reaction:

$$
\mathrm{O}_{2}+2 \mathrm{H}^{+}+2 e^{-} \rightarrow \mathrm{H}_{2} \mathrm{O}_{2}
$$


In soils, the presence of microconductors [8], mainly composed by particles of iron and other metals, allows the redox reactions to occur not only near the electrodes but within the entire treated medium, simultaneously at any interfaces between soils and pore water. This way, hydrogen peroxide $\left(\mathrm{H}_{2} \mathrm{O}_{2}\right)$ can be produced as a result of redox reactions. Since soils commonly contain significant amounts of iron, once $\mathrm{H}_{2} \mathrm{O}_{2}$ has been created, hydroxyl radicals $\left({ }^{\circ} \mathrm{OH}\right)$ can be produced, according to the Fenton's catalytic reaction:

$$
\mathrm{Fe}^{2+}+\mathrm{H}_{2} \mathrm{O}_{2}+\mathrm{H}^{+} \rightarrow \mathrm{Fe}^{3+}+\mathrm{H}_{2} \mathrm{O}+{ }^{\bullet} \mathrm{OH}
$$

Hydroxyl radicals are strong non-selective oxidant agents, able to react with most of organic pollutants.

On the whole, the DCTs include two types of processes [1,9]: 1) the electrokinetic transport, including electroosmosis, electromigration and electrophoresis, which lead to the mobilization and removal of metals, radionuclides and polar organic pollutants, and 2) the electro-oxidation, based on the electrochemically induced redox reactions, responsible of the mineralization of immobile organic contaminants. During this experimental investigation, three laboratory tests were performed to investigate the effectiveness of electrooxidation on the PAH contaminated sediments. The trials were performed with a one-dimensional experimental setup for bench scale testing. The setup consisted in a PVC reactor, including a reaction cell $(10 \mathrm{~cm}$ by $10 \mathrm{~cm}$ by $10 \mathrm{~cm})$, a pair of stainless steel plate electrodes and a stabilized DC generator, providing up to $60 \mathrm{~V}$ and up to $5 \mathrm{~A}$. During each experiment, a contaminated sediment specimen, having a mass of about $2 \mathrm{~kg}$, was at first saturated with demineralized water and inserted in the test setup. A direct electric current was generated across the specimen by applying a steady voltage between the electrodes. Testing was continued for a fixed period of time, after which the soil specimen was removed from the cell and analyzed. All the tests were performed at room temperature and were unenhanced, i.e. no conditioning fluid was dosed at the electrode compartments to improve the soil conductivity, to adjust the soil $\mathrm{pH}$ or to promote contaminant migration. Moreover, no hydraulic gradient was applied across the electrodes. The investigated parameters were voltage, current, soil $\mathrm{pH}$, humidity, TOC and PAH contents. The following tests were performed during this study:

- $\quad$ test EO1: duration of 2 weeks, applied voltage $15 \mathrm{~V}(1.5 \mathrm{~V} / \mathrm{cm})$;

- test EO2: duration of 4 weeks, applied voltage $10 \mathrm{~V}(1 \mathrm{~V} / \mathrm{cm})$;

- test EO3: duration of 4 weeks, applied voltage $20 \mathrm{~V}(2 \mathrm{~V} / \mathrm{cm})$.

The main results obtained across the presented remediation technique are shown in the next paragraph.

\section{Results and risk assessment methodology}

Based on the results of the experimental part of the study, chemical oxidation proved to be an effective remediation technology for the contamination of concern. Different oxidants and different reagent dosages showed different removal efficiencies. The best removal percentages were achieved with: 
modified Fenton's reagent (100mmols of $\mathrm{H}_{2} \mathrm{O}_{2}$ per 30g-sample of sediments); hydrogen peroxide ( $25 \mathrm{mmols}$ of $\mathrm{H}_{2} \mathrm{O}_{2}$ per $30 \mathrm{~g}$-sample); potassium permanganate (50mmols and $100 \mathrm{mmols}$ of $\mathrm{KMnO}_{4}$ per $30 \mathrm{~g}$-sample). The electro-oxidation showed to be able to achieve a very good PAH removal (above 90\%) after a four-week treatment. The applied voltage seems to have a limited influence on the efficiency of the remediation action, good results being achieved with specific voltages as low as $1 \mathrm{~V} / \mathrm{cm}$, with low energy expenditures, while the remediation efficiency proved to increase significantly with process duration. According to the results achieved, both techniques proved to be effective for the remediation of PAH contaminated sediments and to be able to meet the remediation goals. Chemical oxidation seems amenably applicable only in ex situ remediation actions, because the low permeability of the sediments of concern, constrains its in situ applicability; on the opposite electro-oxidation is thought to be easily applicable for both in situ and ex situ remediation actions. The main results considering both technologies for the treatment of PAH contaminated sediments are presented in Table 1 (for chemical oxidation only the highest and lowest values of final concentrations are reported):

Table 1: $\quad \mathrm{PAH}$ concentrations in sediments before and after applying treatment techniques.

\begin{tabular}{|c|c|c|}
\hline \multirow{3}{*}{$\begin{array}{c}\text { Original } \\
\text { concentrations }\end{array}$} & Compound & [mg/kgss] \\
\hline & Benzo(a)pyrene & 142.70 \\
\hline & Total PAHs & 2816.40 \\
\hline \multirow{4}{*}{$\begin{array}{l}\text { Chemical } \\
\text { oxidation }\end{array}$} & "Benzo(a)pyrene $\min _{\min }\left(\mathrm{PP}_{2}\right)$ & 0.7 \\
\hline & Total PAHs $s_{\min }\left(\mathbf{M F}_{50.1}\right)$ & 69.06 \\
\hline & "Benzo(a)pyrene $\max _{\max }$ (HP1) & 105.40 \\
\hline & Total PAHs $_{\max }(\mathrm{HP} 1)$ & 1586.41 \\
\hline \multirow{8}{*}{$\begin{array}{l}\text { Electrochemical } \\
\text { oxidation }\end{array}$} & Benzo(a)pyrene (EO1) & 0 \\
\hline & Total PAHs (EO1) & 135.843 \\
\hline & "Benzo(a)pyrene (EO2) & 19 \\
\hline & Total PAHs (EO2) & 327.143 \\
\hline & Benzo(a)pyrene (EO3) & 3.9 \\
\hline & Total PAHs (EO3) & 96.9 \\
\hline & Benzo(a)pyrene (EO4) & 6.0 \\
\hline & Total PAHs (EO4) & 64.5 \\
\hline
\end{tabular}

Once that PAH concentrations in sediments were assessed, it is important to be able to decide which remediation techniques is most appropriate to be applied. At this point, tools as risk assessment could play an important role for the decision-makers. Consequently, the risk in the interested area was assessed applying the methodology proposed by the United States Environmental Protection Agency (US EPA) [10,11]. For applying the methodology, software $\left(\mathrm{HRA}_{\mathrm{IRC}}\right)$ was created in the frame of a co-supervised $\mathrm{PhD}$ research [3]. The methodology includes four steps: 1. hazard identification (review key research to 
identify any potential health problem that a chemical can cause), 2. exposure assessment (assessment of the amount, lasting, and pattern of exposure to a chemical), 3. dose-response assessment (estimation of the relationship between dose, or level of exposure to a substance, and the incidence and severity of an effect) and 4. risk characterization (assessment of the risk from a chemical in term of cancer or other illnesses in the population. Generally, all these four steps could be influenced by various factors: pollutant and source type, meteorology and climatology, orography, use of soil, global population distribution and behaviors and, last but not least, suitable methodologies and tools for assessing the risk. So, the applied mathematical model is the one proposed in 2003 by the Office of Environmental Health Hazard Assessment (OEHHA) from California, USA and published in The Air Toxics Hot Spots Program Manual for Preparation of Health Risk Assessments. The main supposition in order to be able to assess the individual risk is that the remediate area is dedicated to a residential use. Considering that the residential area is developed after the soil remediation, no deposition from the contamination source exists. As a result, the main exposure pathway is soil ingestion.

\section{Discussion and conclusions}

With the aim of assessing how the individual risk through the soil ingestion pathway in a residential area is changing, the HRA $_{\text {IRC }}$ software based on MATLAB $^{\circledR}$ was applied. PAH concentrations in sediments before and after applying remediation techniques were applied. The associated individual risks to every single concentration are illustrated in Table 2. It is known that an acceptable individual risk is $10^{-6}$ which means one case of cancer over one million of exposed people (World Health Organization). B(a)P oral cancer potency (or slope factor) considered for assessing the risk through the soil ingestion pathway was $1.2 \times 10^{1}\left(\mathrm{mg} /\left(\mathrm{kg}^{*} \text { day }\right)\right)^{-1}$ [12]. Concerning human health risk, in order to evaluate the worst scenario as well as to avoid a risk underestimation, the highest values of their range were chosen for some parameters; it was the same related to $\mathrm{PAH}$ cancer potency for which $\mathrm{B}(\mathrm{a}) \mathrm{P}$ oral cancer potency was chosen. The obtained results showed the importance of using

Table 2: $\quad$ B(a)P concentrations in sediments before and after applying treatment techniques and associated individual risks (IR).

\begin{tabular}{||c|l||c||}
\hline \multirow{2}{*}{$\begin{array}{c}\text { Original } \\
\text { concentrations }\end{array}$} & Compound & {$[-]$} \\
\cline { 2 - 3 } & Benzo(a)pyrene & $5 \times 10^{-4}$ \\
\hline \hline \multirow{2}{*}{$\begin{array}{c}\text { Chemical } \\
\text { oxidation }\end{array}$} & Benzo(a)pyrene ${ }_{\min }\left(\mathrm{PP}_{2}\right)$ & $2 \times 10^{-6}$ \\
\cline { 2 - 3 } & Benzo(a)pyrene ${ }_{\max }(\mathrm{HP} 1)$ & $4 \times 10^{-4}$ \\
\hline \hline \multirow{3}{*}{$\begin{array}{c}\text { Electrochemical } \\
\text { oxidation }\end{array}$} & Benzo(a)pyrene (EO1) & no risk \\
\cline { 2 - 3 } & Benzo(a)pyrene (EO2) & $7 \times 10^{5}$ \\
\cline { 2 - 3 } & Benzo(a)pyrene (EO3) & $1 \times 10^{-5}$ \\
\cline { 2 - 3 } & Benzo(a)pyrene (EO4) & $2 \times 10^{-5}$ \\
\hline
\end{tabular}


risk assessment as a tool in choosing the most appropriate techniques for sediments (soil) remediation. The table 2 underlines the most appropriate techniques which could be used in order to ensure an acceptable human health individual risk regarding $\mathrm{B}(\mathrm{a}) \mathrm{P}$ (for $\mathrm{PAH}$ it will be followed the same path for calculating the human health individual risk).

Using appropriate methodologies and tools it becomes possible not only to decide which remediation technology to adopt, but also what kind of destination could have the remediate soil.

The illustrated approach demonstrates that the assessment of the human health effects must really become an important component of environmental assessment. In this way, decision-makers will become able to develop appropriate mitigation measures with regard and to reduce or even to eliminate the negative impact from human activities. The presented approach could be adopted for optimizing waste management options not only related to techniques for soil remediation.

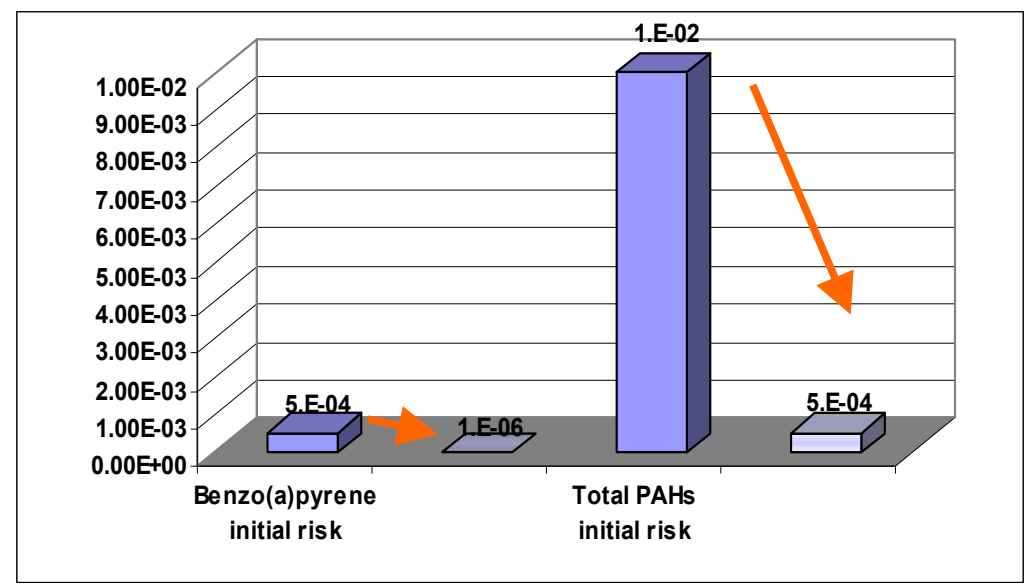

Figure 1: Individual Risk Trend as a consequence of electrochemical oxidation (EO1).

\section{References}

[1] BNL (Brookhaven National Laboratory), Technology fact sheet, Peconic river remedial alternatives, Electrochemical Remediation, 2001.

[2] I.P. Bossert, R. Bartha, Structure-biodegradability relationships of polycyclic aromatic hydrocarbons in soil. Bulletin of Environmental Contaminant Toxicology, vol. 37, 1986, pp. 490-495.

[3] Cocarta D. M., Public Health Impact from Waste-to-Energy Plants, PhD Thesis based on a bilateral agreement between University "POLITEHNICA" of Bucharest, Romania and University of Trento, Italy, April 2007. 
[4] M.P. Cuypers, T.C. Grotenhius, W.H. Rulkens, Characterization of PAH contaminated sediments in a remediation perspective. Water Science Technology, 1998, vol. 37, no. 6-7, 1998, 157-164.

[5] R.G. Harvey, Polycyclic Aromatic Hydrocarbons, Wiley-VCH Publishers, 1997.

[6] P. Henner, M. Schiavon, J. Morel, E. Lichtfouse, Polycyclic aromatic hydrocarbons (PAH) occurrence and remediation methods. Analysis, Vol. 25, no. 9-10, November 1997, pp M56-M59.

[7] J. G. Ibanez, Electrochemical remediation of the environment: fundamentals and microscale laboratory experiment, Centro Mexicano de Quimica en Microescala, Universidad Iberoamericana, D. F. Mexico, 2002.

[8] ITRC (Interstate Technology Regulatory Council), Technical and Regulatory Guidance for In Situ Chemical Oxidation of Contaminated Soil and Groundwater, 2nd Edition. ITRC, ISCO Team, Washington D.C, 2005.

[9] D. Rahner, G. Ludwig, J. Röhrs, Electrochemically induced reactions in soils - a new approach to the in-situ remediation of contaminated soils? Part 1: The microconductor principle. Electrochimica Acta, vol. 47, 2002, pp. 1395-1403.

[10] OEHHA, The Air Toxics Hot Spots Program Guidance Manual for Preparation of Health Risk Assessments, The Air Toxics Hot Spots Program Risk Assessment Guidelines, USEPA, 2003.

[11] US EPA, Methodology for Assessing Health Risks Associated with Indirect Exposure to Combustor Emissions, EPA 600/R-98/137, Methodology for Assessing Health Risks Associated with Multiple Pathways of Exposure to Combustor Emissions, Update to EPA/600/6-90/003, US Environmental Protection Agency, 1998.

[12] US EPA, Air toxics Hot Spots Program Risk Assessment Guidelines, Part II, Technical Support Document for Describing Available Cancer potency Factors, California Environmental Protection Agency, May 2005.

[13] L. Van Cauwenberghe, Electrokinetics, Technology overview report, GWARTAC (Ground-Water Remediation Technologies Analysis Center), Pittsburgh, PA, 1997. 